\title{
Crisis Management at the BBC in Light of the Savile, Newsnight and MacAlpine Allegations
}

\author{
Yanjin Zheng \\ School of Government, Beijing Normal University, Beijing, 100875, China; \\ zhengyanjin@hotmail.com
}

Keywords: Image Repair Strategies, Media crisis, Crisis communication.

\begin{abstract}
This study focuses on the three consecutive BBC crises that happened in 2012 and its use of crisis response strategies and image repair strategies in an attempt to repair the damage. As the media crises are rarely researched, so it is essential to understand the difference of media industry. Benoit's $(1995,1997)$ image repair strategies works as the basic structure to analyze BBC's image repair strategies. The lessons taken from the BBC crisis communication were the basis of the recommendations on how the media organization should conduct the crisis management plan.
\end{abstract}

\section{Introduction}

It was no surprise to see political scandals, corporation bankruptcy on the screen of television, the front-page of newspaper, and headline of news websites. News media always keep eyes on during serious events to inform citizens, the public therefore learn what the event is and what the impact on their life. So organizations treat media as a significant channel and stakeholder to deliver intended messages and control development of crisis (Lippmann. 1922[1]). However, the ironic thing is that now the news reporters themselves have become the main body of the crisis reporting in the global landscape, and the frequency of media crisis is quite astonishing. Nowadays, most research either focused on major corporate crises or some natural disasters. For instance, the BP oil spill and Japan's nuclear crisis: Fukushima. Little research has yet been done for crises within media industries, and most media organizations are still reluctant and unprofessional even if some of them had frequently faced with unfavorable events. Thus, it is imperative to evaluate some media crises, to figure out the real dilemma that faced by media enterprises, to observe how the responses and behaviors of media entity worked, and to provide right knowledge for media companies to prepare for such crises.

\section{Literature Review}

Many scholars have contributed to the research of crisis communication and how to deal with crisis communication effectively. Some basic principles are created to help the organization to better cope with unfavorable events. For example, the company needs to give a quick response in 'golden hour' to fill the information void and avoid misinformation (Regester et al. 2008[2]), the key thing in the crisis communication is to change the public's perception since "perceptions are more important than the reality" (Benoit, 1997. P.178[3]). The application of image restoration theory can reduce reputational damage and maintain positive images of organisations (Coombs, 1995[4]). Bill Benoit (1995)'s image repair strategies framework has been widely used in both academic and practical field for its suitability and appropriateness. This framework is fitted for this study since it concentrates on the organization's identity, which is most threatened during crises. Besides it is beneficial for us to understand the application of various crisis strategies, divide them into related groups and then discuss the effects. There are five categories involved in image repair discourses: Denial, Evasion of Responsibility, Reducing Offensiveness of Event, Corrective Action, Mortification (Benoit, 1997, pp.180-181[3]).

$\mathrm{BBC}$ appeared to be the best choice for the following reasons. First, the organisation was experiencing the biggest reputational crises in its history, which threaten the foundation of the organisation: Trust. Second, the cases within the BBC were intense, devastating, and also those three consecutive crises are interrelated and interacted. For instance, the outburst of the "Newsnight" 
scandal was directly caused by dropping the Savile investigation in 2011, and Lord McAlpine scandal erupted simply because BBC want to shift public's attention away from organization itself. This series of crises enable the researcher observing the change of crisis management strategies through a chronological approach. Third, BBC, as a public service broadcaster, the conflict of maintaining public interest and seeking for profit is more centred than others. Fourth, as an integrated conglomerate, BBC provides services ranging from print, broadcasting and digital platforms, which is very similar with other global media conglomerates like News Corp, so the crisis feature within $\mathrm{BBC}$ can be highly representative in a bigger scope. Finally, it is convenient to collect data and get valuable opinions from academic staffs in Cardiff University. Professor Richard Sambrook, the former director of Global News at the BBC and the global vice-chairman of Edelman. Furthermore, Professor Duncan Bloy, who is an experienced scholar on media law, can provide insights on related legal problems including both civil and criminal.

\section{Methodology}

Yin (2009[5]) suggested the purpose of case studies is to give answers to "how" and "why" questions, so an understanding of nature and complexity of media crises may obtain through applying existing theory into new settings. After using case studies as the foundation of media crises research, content analysis and interviews are combined to supplement and reinforce the research. As a systematic, objective method, content analysis has been used quantitatively to manifest latent content and features through measuring variables like word count, sentence length, frequency and prominence (Dominick and Wimmer, 2006[6]). Furthermore, as Malhotra (2010[7]) asserted that in-depth interviews can provide additional insight and understanding for a particular topic, issue or situation. The sample was selected from three U.K based newspapers: the "Sun", the "Daily Mail" and the "Guardian". The rationale for choosing these three papers is because the crises were more UK-based and all newspapers' targeted readerships were various. The Nexis UK database was used to retrieve newspaper articles appearing in three UK newspapers from 28 September 2012 to 31 December 2012. Cross searching were used since three cases are closely linked. The terms "Jimmy Savile Scandal”, "Lord McAlpine" "Newsnight" and "BBC" were collectively used in searching. Duplicated and irrelevant articles were removed by screening the headlines and lead paragraphs. At the end, totally 118 news articles were collected (Sun 16, Daily Mail, 42 and Guardian, 60).The timeline of 27 September, 2012 to 31 December, 2012 was selected for the following reasons: 1) the time period includes the most important stages of the crises, 2) the time period includes the most intensive coverage of the events, and 3 ) the time period reflects changes in media coverage due to the usage of different strategies. In terms of interview, the respondents were contacted by e-mail at first, and then interviewed face-to-face in the interviewees' offices for about 2-3 hours. To guarantee the desired information within key areas is covered as well as the accuracy of information, conversations are all recorded and repeatedly confirmed. In addition, for the inconsistent and blurred part, emails contacts are supplemented later.

\section{Findings}

The most used image strategies in the Savile case and Newsnight case are Denial; followed by Reducing Offensiveness and Evading Responsibility. In the Savile case, when using Denial, BBC usually showed the corporation's attitude to handle this crisis, but they tended to indicate the whole event is more individual behavior rather than organizational misconduct. Sambrook confirmed that a common way for BBC to handle the crisis is to quickly allocate blame to an individual, then it can tell the public, politicians and newspapers that the problem solved as the person is fired or forced to step aside. For the "Corrective action", the BBC promised that they would cooperate with the police to provide evidence. Moreover, Lord Patten, Chairman of the BBC Trust, stated radical internal restructuring would be made to prevent similar crisis from happening again.

Comparing three crises, in newspapers' reports, the main image repair strategies were still "Denial" and "Reduce offensiveness", but the usage of "Corrective action" and "Mortification gradually 
increased. It can be generalized that with the continuous development of crises, BBC's attitude changed, as they needed to cool down the whole concentration on organization.

The analysis showed the "Denial" and the overall image of the organization was negatively correlated, while "Corrective Action" and "Mortification" show a opposite direction. Sambrook claimed that the negativity may be caused by the contradiction between corporations' messages and the Metropolitan police's one. When an organization actively takes responsibility and ask for stakeholders' forgiveness, the higher evaluation it can get.

The overall quality of the organization's response strategy is divided in three aspects: 1). Quickness. There only have a limited number (5 out of 31)of samples showed the index of quickness, the speed is quite slow. From the timeline of three crises, the responding intervals shorten as well. The first and second took two days for first statement, while the third one only took one day. Hence, the crisis learning can indeed bring changes to organization on its “quickness”.2)Initiative. Generally, BBC took passively strategies in first two events and proactive strategy in last one. It was suggested by Professor Duncan Bloy, that it is understandable for organization like BBC to stay alert because of possible legal consequences. 3). Consistency. Generally speaking, the performance of BBC in three crises is inconsistent. For example, in Savile event, the wrong information was published at first, and then the boss of BBC proved the inaccuracy of messages when questioned in Parliament. Such contradicted information raised the question that organizations are too arrogant and hierarchical, thus its image and reputation was still deteriorating even after apologizing.

\subsection{Other Findings}

There are also some extra findings need to be noticed. First. The degree of involved legal investigation can have a decisive role on organisation's control towards crises. In the UK, the criminal law can lead to someone going to prison or to be fined. While for civil law, it is more about compensation and no juries involved. So in a civil case such as defamation organisations (McAlpine case) can soon finish cases by offering compensation to victims. However in the criminal cases, that result cannot be reached as the police and the prosecution service will reject money compensation. So it less likely that BBC holds control over the police and prosecution services. Thus, one thing here with a crime is that the organisation has to be highly circumspect and to be very limited what they can say when involved people are charged with serious criminal offences. But for the organisation that is in crises, the waiting period can be a giant information void with difficulty to fill with, especially when the proliferation of the Internet has empowered the general public to have their words be heard and spread widely.

Second, leadership and organizational structure do matter in crisis management. Provided that the leader responds to a crisis and takes the public command, organisation's reputation could be saved. When comes to George Entwistle, the last Director General, who had to deal with the biggest scandal in the BBC's history after he took the position only for 15 days. Obviously, he had no experience to sort out the business operation of BBC, and he even did not know how to respond properly. Thus, his unprepared status and slowness to react may reinforce the corporate failure as no proper decision had been made from the centre of management. In terms of organizational structure, Ducan pointed out that the serious imbalance between the production department and the management level has triggered a conflict so that communication failure, internal redundancies and time-consuming pyramid management finally led to the poor performance on crisis management.

\section{Summary}

Based on the analysis, several suggestions are made accordingly. To begin with, media organizations, which are in crisis, do not use "Denial" and "Evade Responsibility" when the whole landscape is still blurred, instead try to run a quick assessment about the crisis type and self-owned resources and information, and then selectively choose response strategies to achieve the desired result. Also when use combined strategies, organization should pay attention to the internal and external consistency of the strategy, when the shift has to be made, the quality of information (e.g. the authenticity of messages) must be strictly controlled and the potential public reaction (e.g. antipathy) as well to avoid the opposite effect. If organization has a good pre-crisis reputation and 
sustained news output with excellent quality, every effort should be made to arouse public memory of the good histories of the organization, all of which can dilute the "toxic" effect of the crisis. For retrospective issues, there is not rush to find excuses, provide documentary or evidence to police to find the victims, make compensation to confirmed victims (e.g. apologise) and keep the public informed.

\section{References}

1. Lippmann, W. Public opinion. New York: Harcourt Brace, 1922.

2. Regester, M., Larkin, J et al. Risk Issues and Crisis Management in Public Relations: A Casebo ok of Best PR (3rd ed). London: Kogan Page, 2008.

3. Benoit, W.L. Image repair discourse and crisis communication. Public Relations Review.Vol.2 3(1997)No.2,p.177-186.

4. Coombs, T. Choosing the rights words: The development of guidelines for the selection of the a ppropriate crisis-response strategies. Management Communication Quarterly. Vol.8 (1995)No. 8,p.447-476.

5. Yin, R., Thousand, S et al. Case Study Research: Design and Methods (4th ed). Blackwell Scie nce Ltd, 2009.

6. Wimmer, R. D., Dominick, J. R et al. Mass media research: An introduction (8th ed.). Belmont: Wadsworth, 2006.

7. Malhotra, N. Marketing Research: An Applied Orientation (6 $6^{\text {th }}$ ed.). New Jersey: Prentice Hall, 2010. 